TAP CHI SINH HOC 2020, 42(1): 111-123

DOI: $10.15625 / 0866-7160 / \mathrm{v} 42 \mathrm{n} 1.13790$

\title{
STUDY OF CYP3A5 GENETIC POLYMORPHISM IN VIETNAMESE KINH ETHNIC GROUP
}

\author{
Vu Phuong Nhung ${ }^{1,2}$, Nguyen Dang Ton ${ }^{1,2}$, Nguyen Hai Ha1,2,* \\ ${ }^{1}$ Institute of Genome Research, VAST, Vietnam \\ ${ }^{2}$ Graduate University of Science and Technology, VAST, Vietnam
}

Received 25 April 2019, accepted 2 January 2020

\begin{abstract}
Cytochrome P450 3A5 (CYP) belongs to the CYP3A cluster, which encode for several enzymes involved in metabolism of various drugs, endogenous substrates as well as exogenous compounds. Among the four genes of CY3A cluster, CYP3A5 plays an important role in pharmacogenetics since this enzyme metabolizes over $30 \%$ of the clinically prescribed drugs. The inter-individual variability in clearance of CYP3A substrates mainly depends on the genetic factors. In the present study, after collecting peripheral bloods samples from 100 unrelated healthy Kinh ethnic group in Vietnam, Sanger sequencing was used in order to determine the CYP3A5 variants responsible for enzyme activity alteration $(* 3, * 6, * 8$ and $* 9)$. It was shown that $C Y P 3 A 5 * 3$ is the most prevalent variant with $67.5 \%$, in which a haft of individuals carrying $* 3$ were homozygous for this allele. In contrast, the variants $* 6, * 8$ and $* 9$ were not found the study subjects. The data observed in current study would support dosing of drugs that metabolized by CYP3A5 and thereby increase treatment outcome.
\end{abstract}

Keywords: CYP3A5, drug metabolism, genetic variant, Kinh ethnic group, pharmacogenetics, tacrolimus.

Citation: $\mathrm{Vu}$ Phuong Nhung, Nguyen Dang Ton, Nguyen Hai Ha, 2020. Study of CYP3A5 genetic polymorphism in Vietnamese Kinh ethnic group. Tap chi Sinh hoc, 42(1): 111-123. https://doi.org/10.15625/0866$7160 / \mathrm{v} 42 \mathrm{n} 1.13790$.

*Corresponding author email: nguyenhaiha@igr.ac.vn

(C2020 Vietnam Academy of Science and Technology (VAST) 


\title{
NGHIÊN CÚU ĐA HÌNH GEN CYP3A5 Ở NGƯỜI KINH VIỆT NAM
}

\author{
Vũ Phương Nhung,1,2, Nguyễn Đăng Tôn ${ }^{1,2}$, Nguyễn Hải Hà 1,2,* \\ ${ }^{1}$ Viện Nghiên cứu hệ gen, Viện Hàn lâm Khoa học và Công nghệ Việt Nam \\ ${ }^{2} \mathrm{Học}$ viện Khoa học và Công nghệ, Viện Hàn lâm Khoa học và Công nghệ Việt Nam
}

Ngày nhận bài 25-4-2019, ngày chấp nhận 2-1-2020

\section{TÓM TẮT}

CYP3A5 là một trong 4 gen thuộc cụm gen $C Y P 3 A$ mã hóa cho các enzyme tham gia chuyển hóa nhiều loại thuốc, các hợp chất nội sinh và các hợp chất xenobiotic khác. Trong đó, CYP3A5 tham gia chuyển hóa hơn $30 \%$ thuốc lâm sàng được kê đơn. Khả năng chuyển hóa thuốc của $C Y P 3 A 5$ cũng như các gen khác thuộc họ $C Y P 3 A$ phụ thuộc chủ yếu vào di truyền. Trong số các biến thể đã biết của $C Y P 3 A 5, * 3, * 6, * 8$ và *9 là các biến thể tạo nên protein bị giảm hoặc không có hoạt tính. Trong nghiên cứu này chúng tôi sử dụng phương pháp giải trình tự trực tiếp để xác định các biến thể quan trọng của gen $C Y P 3 A 5$ bao gồm $* 3,{ }^{*} 6, * 8$ và $* 9$ trên 100 người Kinh khỏe mạnh. Kết quả cho thấy $C Y P 3 A 5^{*} 3$ là biến thể phổ biến nhất với tần số xuất hiện là $67,5 \%$. Năm mươi phần trăm cá thể mang alen *3 có kiểu gen đồng hợp tử $C Y P 3 A 5 * 3 / * 3$. Không có cá thể nào được xác định là mang các biến thể *6, *8 và *9. Dữ liệu thu được của nghiên cứu góp phần nâng cao hiệu quả điều trị các bệnh có sử dụng các loại thuốc chuyển hóa bởi CYP3A5.

Từ khóa: CYP3A5, biến thể di truyền, chuyển hóa thuốc, tacrolimus.

*Địa chỉ liên hệ email: nguyenhaiha@igr.ac.vn

\section{MỞ ĐẦU}

Cytochrome P450 (CYP) là hệ thống chuyển hóa sinh học quan trọng trong cơ thể người. Chúng gồm các enzyme tham gia vào chuyển hóa các hợp chất xenobiotic (các loại thuốc và các hóa chất từ môi trường) và hợp chất endobiotic (axit béo, steroid, axit mật) (Lolodi et al., 2017; Rendic, 2002). Ở người có 18 họ gen $C Y P$ (Nebert et al., 2013) trong đó $C Y P 1, C Y P 2$ và $C Y P 3$ là 3 họ gen linh hoạt nhất, làm trung gian chuyển hóa cho nhiều hợp chất xenobiotic khác nhau (Lewis, 2004; Nebert et al., 2013). Khoảng 80\% tổng số thuốc lâm sàng được chuyển hóa bởi 20 gen thuộc 3 họ gen này (Zanger \& Schwab, 2013), trong đó phân họ CYP3A tham gia chuyển hóa, hơn $50 \%$ tổng số các loại thuốc thường được kê đơn (Burk et al., 2004; Zanger et al., 2008).
Họ gen $C Y P 3$ chỉ có một phân họ $C Y P 3 A$, nằm trên nhiễm sắc thể 7q21-q22 gồm 4 gen (CYP3A4, CYP3A5, $C Y P 3 A 7$ và $C Y P 3 A 43)$ và 2 gen giả (CYP3AP1 và $C Y P 3 A P 2)$ (Danielson, 2003). Nhiều đa hình trên gen $C Y P 3 A$ đã được chứng minh là làm giảm/mất hoạt tính của các enzyme tương ứng (Dai et al., 2001; Josephson et al., 2007; Kuehl et al., 2001; Werk et al., 2014). Do đó, các chất nền chuyển hóa phụ thuộc vào hoạt động chức năng của CYP3A có thể không được chuyển hóa hiệu quả khi có sự hiện diện của một trong những đa hình di truyền này. Như vậy, những bệnh nhân mang đa hình này có thể gặp phải tác dụng dược lý quá mức, sốc hay tác dụng phụ do nồng độ thuốc cao trong cơ thể khi không được chuyển hóa hiệu quả. Trên thực tế, các nghiên cứu đã chứng minh yếu tố di truyền có thể chiếm $20-95 \%$ sự thay đổi 
trong lưu lượng và tác dụng của thuốc trong cơ thể (Ozdemir et al., 2000; Rahmioglu et al., 2011; Sarasamma et al., 2016). Trong số các enzyme thuộc họ CYP3A, CYP3A43 ít đóng góp nhất vào quá trình giải phóng thuốc ra khỏi cơ thể vì biểu hiện của nó rất thấp, hơn nữa, hoạt động xúc tác cũng kém hơn nhiều so với các enzyme khác (Domanski et al., 2001; Westlind-Johnsson et al., 2003). CYP3A7 được cho là ít có đóng góp cho việc ,chuyển hóa thuốc vì nó được biểu hiện ở thai nhi, ít khi thấy ở người trưởng thành (Schuetz et al., 1993; Schuetz et al., 1994; Tateishi et al., 1999). Hai gen tham gia chuyển hóa thuốc nhiều nhất là $C Y P 3 A 4$ và $C Y P 3 A 5$. Đây đều là các gen có nhiều đa hình và cũng là yếu tố chính quyết định tính dược lý hay độc tố khác nhau trong phản ứng thuốc giữa các cá nhân.

CYP3A5 là gen đầu tiên gần tâm động nhất của cụm gen $C Y P 3 A$, gen này nằm trên sợi liên tục (minus) của nhiễm sắc thể $7 \mathrm{q} 22.1$ gồm 13 exon mã hóa cho một protein nặng $52,5 \mathrm{kDa}$ gồm 502 axit amin (Langman et al., 2016). Với nhân HEME và phối tử kim loại sắt, protein $\mathrm{CYP} 3 \mathrm{~A} 5$ có hoạt tính monooxygenase và oxydoreductase có vai trò tham gia các quá trình trao đổi chất steroid, trao đổi chất xenobiotic và quá trình dị hóa oxy hóa thuốc. CYP3A5 biểu hiện ở nhiề̀ cơ quan trong cơ thể nhưng chủ yếu ở gan và ruột non của người trưởng thành (Kuehl et al., 2001). Sự biểu hiện của CYP3A5 và các protein CYP khác ở gan và ống tiêu hóa được cho là nguyên nhân chính ảnh hưởng đến sinh chuyển hóa của các loại thuốc đường uống. Biểu hiện của CYP3A5 chiếm khoảng $10 \%$ đến $30 \%$ tổng số CYP3A ở gan (WestlindJohnsson et al., 2003). Các biến thể của CYP3A5 có mặt trên tất cả các vùng của gen bao gồm 5'upstream, exons, introns và 3'UTR (Lee et al., 2003) và được quy ước từ * 1 đến *10 (hình 1). Những biến thể này có khả năng ảnh hưởng đến sự biểu hiện của mRNA, mức độ biểu hiện và hoạt động xúc tác của protein enzyme, nhưng hầu hết tác động trên mô hìn h in vivo chưa được chứng minh vì tính phức tạp trong hoạt động trao đổi chất của tế bào và cơ thể. Hầu hết các biến thể đã được chứng minh về hậu quả của nó trên mô hình in vitro. Hàng loạt các biến thể mới đang được phát hiện và bổ sung được thống kê tại trang web https://www.pharmvar.org/gene/CYP3A5.

Như đã nói ở trên, CYP3A4 và CYP3A5 cùng nhau tham gia nhiều nhất phản ứng chuyển hóa thuốc trong cơ thể. Yếu tố di truyền của các gen chuyển hóa là một trong những yếu tố chính quyết định tính chất của các phản ứng thuốc trong mỗi cá nhân. Nhưng xét về khía cạnh này, sự khác nhau giữa các đa hình của $C Y P 3 A 5$ gây ra sự thay đổi rõ rệt hơn hẳn so với đa hình của $C Y P 3 A 4$. Hầu hết các biến thể của $C Y P 3 A 4$ chưa được chứng minh rõ ràng về chức năng và cũng không phải là nguyên nhân chính dẫn đến sự thay đồi trong các phản ứng chuyển hóa thuốc (Lamba et al., 2002). Trong khi đó hầu hết đa hình của CYP3A5 đã được chứng minh là tạo ra các enzyme không chức năng, ảnh hưởng nghiêm trọng tới quá trình chuyển hóa thuốc bởi enzyme này (Lamba et al., 2012). Trong số các đa hình, $C Y P 3 A 5^{*} 3$ là biến thể quan trọng nhất gây ra sự suy giảm nghiêm trọng trong chức năng của CYP3A5. Hơn nữa, trong các biến thể của CYP3A5 đây là alen phổ biến nhất trong tất cả các quần thể đã được nghiên cứu (Koch et al., 2002; Xie et al., 2004). Các biến thể khác ít phổ biến hơn nhưng cũng gây hậu quả suy giảm chức năng của enzyme CYP3A5 bao gồm *6, *8 và *9. Có thể thấy, với khả năng chuyển hóa nhiều loại thuốc của các CYP3A thì các dữ liệu di truyền liên quan tới các enzyme này là cần thiết. Trong khi đó trên thế giới mới chỉ có một công bố về đa hình CYP3A5 trên 78 người Kinh (Veiga et al., 2009). Ở Việt Nam, cho tới nay chưa có công bố nào về nghiên cứu đa hình di truyền của gen $C Y P 3 A 5$. Sự đóng góp về dữ liệu di truyền của các $C Y P 3 A$ nói chung và $C Y P 3 A 5$ nói riêng trong tương lai là rất cần thiết trong công tác quản lý sử dụng thuốc và điều trị bệnh.

Mục tiêu của nghiên cứu này nhằm bổ sung dữ liệu về đa hình gen $C Y P 3 A 5$ đang còn thiếu ở Việt Nam. Bước đầu chúng tôi sử dụng phương pháp giải trình tự trực tiếp để 
xác định các biến thể có ảnh hưởng tới chức năng của CYP3A5 đã được công bố bởi nhiều nhóm nghiên cứu trên thế giới bao gồm các biến thể *3, *6, *8 và *9.

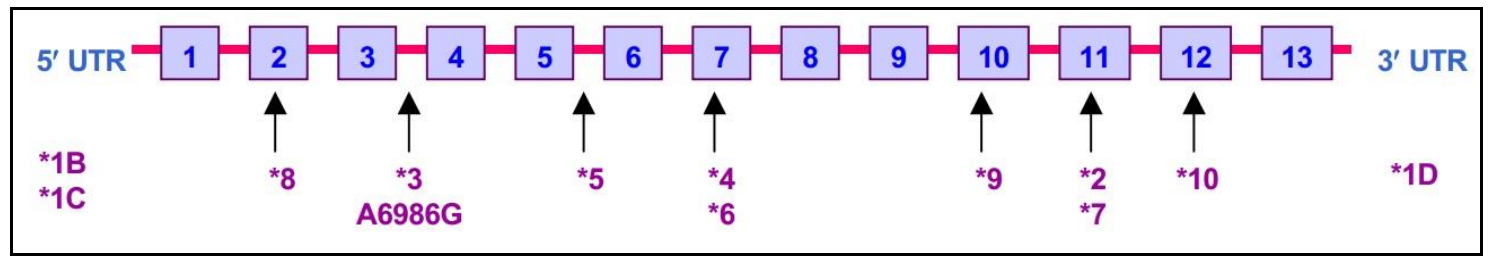

Hình 1. Phân bố của các biến thể trên gen CYP3A5 (*1-*10) (Lamba et al., 2002)

\section{VÂT LIỆU VÀ PHƯƠNG PHÁP NGHIÊN CúU}

Một trăm mẫu máu người Kinh khỏe mạnh (46 nam, 54 nữ) được Bệnh viện Đại học Y Hà Nội cung cấp, được sử dụng để tách DNA dùng cho các bước phân tích di truyền. Mục đích sử dụng mẫu trong nghiên cứu đã được giải thích với các đối tượng nghiên cứu trước khi tiến hành lấy mẫu. Thông tin của người hiến tặng được bảo mật, mỗi ống chứa mẫu máu của mỗi người riêng biệt và được mã hóa. Toàn bộ mẫu máu được bảo quản lạnh ngay sau khi lấy và trong suốt quá trình vận chuyển trước khi tiến hành các thao tác phân tích tiếp theo, đảm bảo toàn bộ mẫu hiến tặng không bị biến đổi. Nghiên cứu này đã thông qua Hội đồng Y đức của Viện Nghiên cứu hệ gen, Viện Hàn lâm Khoa học và Công nghệ Việt Nam.

\section{Tách chiết DNA tổng số từ máu}

DNA tổng số được tách chiết từ máu ngoại vi sử dụng Exgene ${ }^{\mathrm{TM}}$ Blood SV mini Kit (GenAll, Hàn Quốc). Sau đó, DNA tổng số được kiểm tra bằng điện di trên Agrose $0.8 \%$ và nồng độ $\mathrm{DNA}$ được đánh giá bằng Qubit dsDNA HS Assay Kit (Life Technologis, USA). DNA tổng số được lưu ở $(-) 20^{\circ} \mathrm{C}$ phục vụ cho các thí nghiệm tiếp theo.

\section{Thiết kế mồi đặc hiệu và PCR khuếch đại vùng gen quan tâm}

Các cặp mồi đặc hiệu dùng trong nghiên cứu được thiết kế bằng phần mềm Primer 3 (v.0.4.0) dựa trên trình tự gen tham chiếu của CYP3A5. Các đặc trưng và tính đặc hiệu của mỗi cặp mồi được kiểm tra bằng các công cụ IDT OligoAnalyzer Tool và In silico PCR amplification. Các mồi được tổng hợp và cung cấp bởi công ty Sinh hóa Phù Sa-Cần Thơ. Trình tự các cặp mồi được liệt kê trong bảng 1 .

Bảng 1. Trình tự mồi được sử dụng để khuếch đại đặc hiệu các vùng gen CYP3A5

\begin{tabular}{|c|l|c|c|}
\hline Biến thể & \multicolumn{1}{|c|}{ Trình tự mồi (5'-3') } & Size $(\mathrm{bp})$ & Ta $\left({ }^{\circ} \mathrm{C}\right)$ \\
\hline CYP3A5*3 & $\begin{array}{l}\text { F: CTTGCAGCATTTAGTCCTTGTGAG } \\
\text { R: CTGATCACGTCGGGATCTGTGA }\end{array}$ & 503 & 59 \\
\hline CYP3A5*6 & $\begin{array}{l}\text { F: AGGTGAGTCTAACTCAGCTTG \# } \\
\text { R: GACAGCTAAAGTGGTGAGGG \# }\end{array}$ & 578 & 58 \\
\hline CYP3A5*8 & $\begin{array}{l}\text { F: CTTGACCATTCCAGTTCCTGA \# } \\
\text { R: CTACAGGCATGGGCTACCATA \# }\end{array}$ & 476 & 56 \\
\hline CYP3A5*9 & $\begin{array}{l}\text { F: AGGATCATTCAAGGCACACAC \# } \\
\text { R: ATG CTT CTGCCAGTAGCAAC }\end{array}$ & 680 & 58 \\
\hline $\begin{array}{l}\text { F: Forward Primer-Mồi xuôi R: Reverse Primer-Mồi ngược } \\
\text { Size: Kích thước đoạn DNA đặc hiệu được nhân bản } \\
\text { Ta: Nhiệt độ gắn mồi } \\
\text { \#: Trình tự mồi được tham khảo từ nghiên cứu của (Xie et al., 2004) }\end{array}$ \\
\hline
\end{tabular}


Phản ứng PCR được thực hiện với tổng thể tích cuối cùng của mỗi phản ứng là $25 \mu \mathrm{l}$ bao gồm: $10 \mathrm{ng}$ DNA tổng số, $1,2 \mu 1$ mỗi mồi $(10 \mathrm{pmole} / \mu \mathrm{l}), 12,5 \mu \mathrm{l}$ Taq $2 \mathrm{X}$ Mastermix (New England Biolab, USA), $1 \mu 1$ DMSO, 7,9 $\mu 1$ nước khử ion (Life Technologies, USA). Chu trình nhiệt: $95^{\circ} \mathrm{C} / 5 \mathrm{~min}, 40 \mathrm{chu}$ kỳ $\left(95^{\circ} \mathrm{C} / 15 \mathrm{~s}-56-59^{\circ} \mathrm{C} / 15 \mathrm{~s}-68^{\circ} \mathrm{C} / 30 \mathrm{~s}\right), 8^{\circ} \mathrm{C} / 5 \mathrm{~min}$, $4^{\circ} \mathrm{C} / \infty$. Sản phẩm của phản ứng được kiểm tra bằng điện di trên gel Agrose $1 \%$. Sản phẩm PCR sau đó được tinh sạch bằng E.Z.N.A. Cycle Pure Kit và bảo quản ở $(-) 20^{\circ} \mathrm{C}$.

\section{Giải trình tự Sanger}

Sản phẩm PCR đã tinh sạch được thực hiện phản ứng cycle sequencing với BigDye V3.1 (Applied Biosystems) theo 2 chiều xuôi và ngược. Chu trình nhiệt như sau: $96^{\circ} \mathrm{C} / 1$ min, 25 chu kỳ $\left(96^{\circ} \mathrm{C} / 10 \mathrm{~s}, \quad(-) 50^{\circ} \mathrm{C} / 5 \mathrm{~s}\right.$, $\left.(-) 60^{\circ} \mathrm{C} / 4 \mathrm{~min}\right), 4^{\circ} \mathrm{C} /{ }^{\circ}$. Sản phẩm này sau đó được tinh sạch với ethanol, biến tính trong HiDi formamide (Thermo Scientific, USA) ở $95^{\circ} \mathrm{C}$ trong 2 phút trước khi làm lạnh nhanh trên đá. Điện di mao quản được thực hiện trên máy giải trình tự 3500 (Applied Biosystems, USA).

\section{Phân tích kết quả và xử lý dữ liệu}

Trình tự nucleotide tham chiếu của gen CYP3A5 (đoạn trình tự nucleotide từ 99680026-99648189) được lấy từ cơ sở dũ liệu nucleotide của NCBI mang số hiệu NG_007938. Các trình tự nucleotide của mẫu so sánh với trình tự tham chiếu bằng phần mềm BioEdit để xác định nucleotide tại vị trí quan tâm.

Các thuật toán thống kê được thực hiện trên Microsoft Excel 2010. Định luật cân bằng Hardy-Weinberg được áp dụng để đánh giá tần số kiểu gen của quần thể. Tiêu chuẩn chi bình phương $\left(\chi^{2}\right)$ được áp dụng để so sánh tần số alen trong nghiên cứu này với các quần thể được công bố khác và để đánh giá trạng thái cân bằng của quần thể so với định luật HardyWeinberg. Phân bố chuẩn tắc được dùng để ước lượng khoảng tin cậy cho tỷ lệ các alen. Tất cả các phép xác suất thống kê dùng trong nghiên cứu đều được tiến hành với độ tin cậy 95\% (95\% CI).

\section{KẾT QUẢ VÀ THẢO LUẬN}

\section{Kết quả tách chiết DNA tổng số}

Để chuẩn bị cho phân tích di truyền, các mẫu máu được tách chiết DNA tổng số sử dụng Exgene ${ }^{\mathrm{TM}}$ Blood SV mini Kit. Sau khi tách chiết, DNA tổng số được kiểm tra bằng điện di trên gel Agrose 0,8\% (hình 2). Kết quả điện di cho thấy các băng điện di sáng và gọn, thể hiện DNA tổng số đảm bảo độ tinh sạch và không bị đứt gãy, đủ chất lượng để tiến hành các phân tích tiếp theo. Nồng độ DNA tách chiết đã được đo cho thấy hàm lượng DNA các mẫu nằm trong khoảng 20 $110 \mathrm{ng} / \mu \mathrm{l}$.

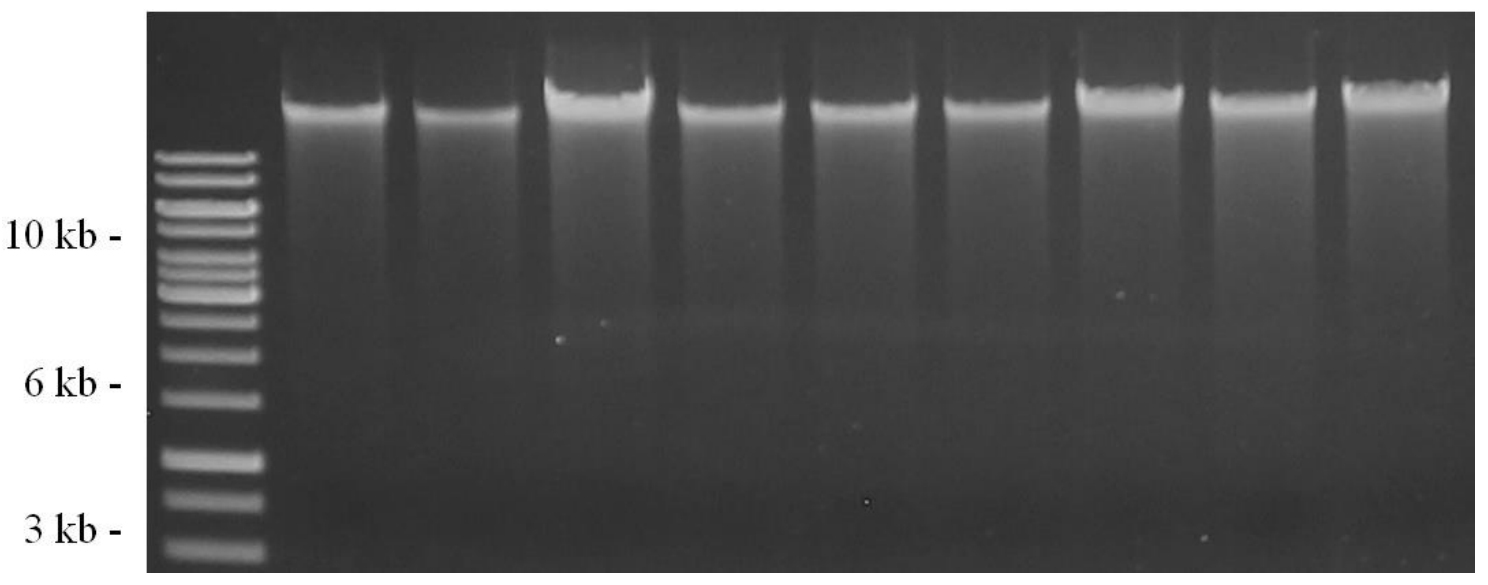

Hình 2. Điện di đồ sản phẩm tách chiết DNA tổng số 
Kết quả PCR đặc hiệu và giải trình tự các vùng gen $C Y P 3 A 5$

Chúng tôi đã tiến hành phản ứng PCR để khuếch đại đặc hiệu các vùng gen $C Y P 3 A 5$ mang các biến thể *3, *6, *8 và *9 trên tất cả 100 mẫu nghiên cứu. Sản phẩm PCR được kiểm tra bằng điện di trên gel Agrose $1 \%$. Hình ảnh điện di cho thấy chúng tôi đã khuếch đại thành công trình tự đặc hiệu cho tất cả các mẫu, kích thước băng điện di phù hợp với tính toán lý thuyết (hình 3 ). Sản phẩm PCR sau đó được tinh sạch để sử dụng cho các phản ứng giải trình tự tiếp theo. Chúng tôi đã giải trình tự thành công các vùng gen CYP3A5 chứa các biến thể *3, *6, *8 và *9 trên 100 mẫu người Kinh. Tất cả các đoạn gen này đều được giải trình tự trên cả 2 chiều xu ôi và ngược để xác định chính xác các biến thể quan tâm.
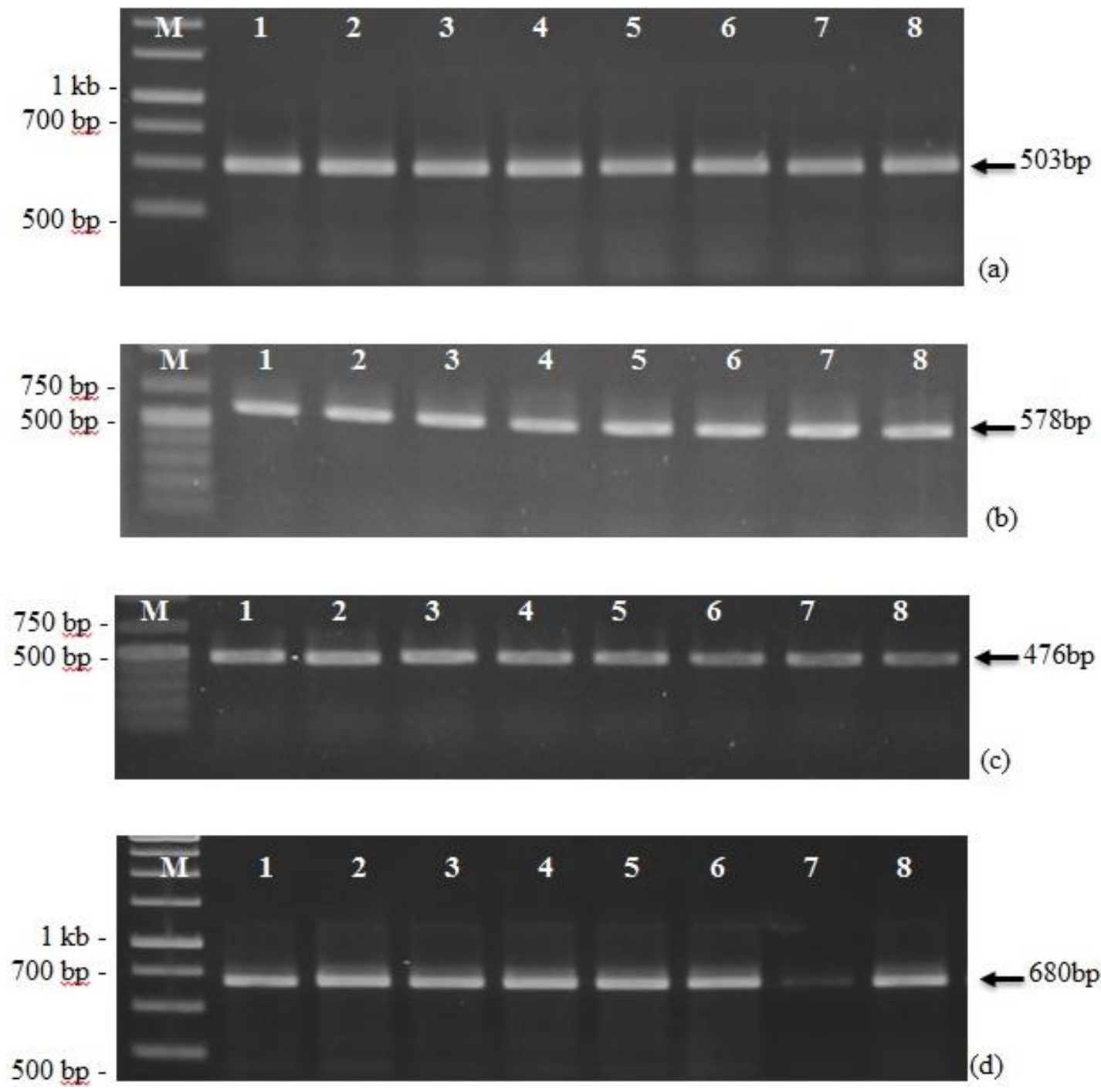

Hình 3. Điện di đồ sản phẩm PCR khuếch đại đặc hiệu các vùng gen $C Y P 3 A 5$, M: Thang DNA chuẩn. 1-8: Sản phẩm PCR $C Y P 3 A 5^{* 3}(\mathrm{a}), * 6(\mathrm{~b}), * 8(\mathrm{c})$ và *9 (d) các mẫu

Kết quả tổng hợp tần số alen và tần số kiểu gen CYP3A5
Đối với biến thể *3, 90\% số người trong nghiên cứu mang ít nhất một alen biến thể 
CYP3A5*3 $(* 1 / * 3$ và *3/*3, n=90) trong khi đó chỉ $10 \%(\mathrm{n}=10)$ số người mang kiểu gen đồng hợp tử kiểu dại $C Y P 3 A 5^{*} 1 / * 1$. Trong số những người mang alen $* 3,50 \%$ có kiểu gen dị hợp tử với alen kiểu dại $(\mathrm{n}=45 / 90)$. Theo đó tần sô alen kiểu dại $C Y P 3 A 5^{*} 1$ được xác định là $32,5 \%$ còn tần số biến thể alen $C Y P 3 A 5^{*} 3$ (6986A>G) là 67,5\%; khoảng tin cậy $95 \%$ cho tần số alen *3 là $61-74 \%$. Với tần số kiểu gen/alen như vậy, quần thể nghiên cứu xấp xỉ đạt trạng thái cân bằng Hardy-Weinberg $\left(\chi^{2}=0,0331 ; \mathrm{p}=0,9677\right)$. Trong $100 \mathrm{mâ} u$ nghiên cứu, không có mẫu nào được xác định là mang các biến thể còn lại bao gồm *6, *8 và $* 9$. Kết quả được hiển thị trong bảng 2 .

Bảng 2. Tần số alen $C Y P 3 A 5^{*} 3$ và kiểu gen trên người Kinh Việt Nam

\begin{tabular}{|l|c|c|c|c|c|}
\hline \multirow{2}{*}{ Tần số } & \multicolumn{3}{|c|}{ Kiểu gen $(\mathrm{n}=100)$} & \multicolumn{2}{c|}{ Alen $\left(\mathrm{n}_{\mathrm{a}}=200\right)$} \\
\cline { 2 - 6 } & $* 1 / * 1$ & $* 1 / * 3$ & $* 3 / * 3$ & $* 1$ & $* 3$ \\
\hline Nghiên cứu này & $10(10 \%)$ & $45(45 \%)$ & $45(45 \%)$ & $65(32,5 \%)$ & $135(67,5 \%)$ \\
\hline Hardy-Weinberg & $10,56 \%$ & $43,88 \%$ & $45,56 \%$ & & \\
\hline & \multicolumn{3}{|c|}{$\chi^{2}=0,0331 ; \mathrm{p}=0,9677$} & & \\
\hline
\end{tabular}

So sánh tần số alen $C Y P 3 A 5 * 3$ ở người Kinh với các quần thể khác trên thế giới

Khi so sánh với các quần thể khác trên thế giới, tần số biến thể $C Y P 3 A 5^{*} 3$ ở quần thể người Kinh trong nghiên cứu của chúng tôi $(67,5 \%)$ thấp hơn so với các quần thể người da trắng $\left(92 \% ; \chi^{2}=148,9845 ; p<0,0001\right)$ và cao hơn so với các quần thể người da đen $\left(19 \% ; \chi^{2}=238,9066, \mathrm{p}<0,0001\right)$. Trong khu vực châu Á, tỷ lệ này không khác biệt nhiều với tần số alen $C Y P 3 A 5^{*} 3$ trung bình của người Nam Á $\left(65 \% ; \chi^{2}=0,3932 ; \mathrm{p}=0,6318\right)$ và Đông Á $\left(72 \% ; \chi^{2}=1,6830 ; \mathrm{p}=0,3486\right)$ nhưng lại thấp hơn rõ rệt so với khu vực Tây Á $\left(90,5 \% ; \chi^{2}=64,1111 ; \mathrm{p}<0.0001\right)$ và $\mathrm{người} \mathrm{da}$ trắng $\left(92 \% ; \chi^{2}=148,9845 ; \mathrm{p}<0,0001\right)$ (bảng $3)$. Tỉ lệ $C Y P 3 A 5 * 3$ trong nghiên cứu này cũng không khác biệt nhiều so với trung bình của các quốc gia Đông Nam Á $(64 \%$, $\left.\chi^{2}=0,7266 ; p=0,4969\right)$. Kết quả trên hoàn toàn phù hợp với một nghiên cứu trước đó công bố về tần số $C Y P 3 A 5^{*} 3$ trên người Việt Nam củ a (Veiga et al., 2009) $\left(66,67 \% ; \chi^{2}=0,0264\right.$; $\mathrm{p}=0,8588$ ) (bảng 3). Sự khác biệt trong phân bố của biến thể $C Y P 3 A 5^{*} 3$ giữa các vùng khác nhau ở châu Á và trên thế giới có thể được giải thích bằng nguyên nhân lịch sử. Thí dụ như Thổ Nhĩ Kỳ là quốc gia có lãnh thổ nằm cả ở châu Âu và Tây Á, có đường biên giới với Hy Lạp và Bungari. Iran cũng là một nước đa sắc tộc, từng trải qua các cuộc tấn công và chiếm đóng của đế quốc Nga và Anh trong lịch sử, do đó, dân số của họ có thể mang bộ gen với nhiều nguồn gốc chủng tộc khác nhau. Bên cạnh đó, áp lực chọn lọc khác nhau ở mỗi khu vực địa lý lên mỗi biến thể di truyền cũng có thể là nguyên nhân dẫn tới sự đa dạng trong phân bố của các biến thể này.

Trong lâm sàng, tacrolimus là một loại thuốc ức chế hệ miễn dịch, có chỉ số trị liệu hẹp (narrow therapeutic index-NTI), thuốc này hiện nay đang được sử dụng rộng rãi cho các bệnh nhân sau ghép tạng (thận, tim) và ghép tế bào gốc máu. Trong gan, tacrolimus được chuyển hóa bởi CYP3A4 và CYP3A5. Trong điều trị, việc quyết định liều tacrolimus khá phức tạp bởi sự khác biệt về dược động học giữa các bệnh nhân có thể dẫn tới các trường hợp: liều điều trị thấp dẫn tới tạng ghép bị loại thải, liều điều trị cao quá mức dẫn tới nguy cơ ngộ độc thuốc (cao huyết áp, ngộ độc thần kinh, ngộ độc thận, tăng đường máu). Tổ chức ứng dụng di truyền dược học trong lâm sàng (Clinical Pharmacogenetics Implementation Consortium-CPIC) đã có những hướng dẫn căn bản trong việc sử dụng loại thuốc này đối với từng kiểu hình chuyển hóa thuốc ở các cá nhân. Trong đó, bệnh nhân mang kiểu gen $C Y P 3 A 5^{*} 1 / * 1$ (chuyển hóa thuốc bình thường) và $C Y P 3 A 5^{*} 1 / * 3$ (chuyển hóa thuốc trung bình) cần sử dụng liều tacrolimus cao hơn 1,5-2 lần so với liều 
chuẩn. Trong khi đó các bệnh nhân mang kiểu gen $C Y P 3 A 5 * 3 / * 3$ (chuyển hóa thuốc yếu) có thể sử dụng liều tacrolimus theo như khuyến cáo thông thường (Birdwell et al., 2015). Với $50 \%$ số cá thể nghiên cứu mang biến thể * 3 có kiểu gen dị hợp tử $C Y P 3 A 5^{*} 1 / * 3$, nghiên cứu này cho thấy tầm quan trọng của việc khai thác thông tin đa hình gen nhằm đưa ra liệu pháp sử dụng thuốc hiệu quả đối với từng bệnh nhân.

Bảng 3. So sánh tần số các alen của $C Y P 3 A 5 * 3$ trên thế giới

\begin{tabular}{|c|c|c|c|c|c|}
\hline \multicolumn{2}{|c|}{ Khu vực } & $\mathrm{n}$ & Tần số *3 & $95 \% \mathrm{CI}$ & Tham khảo \\
\hline \multicolumn{2}{|c|}{$\begin{array}{l}\text { Việt Nam-Nghiên cứu } \\
\text { của chúng tôi }\end{array}$} & 100 & $67,5 \%$ & $61-74 \%$ & \\
\hline \multirow{4}{*}{ Đông Á } & Trung Quốc & 451 & $70 \%$ & $67-73 \%$ & (Liu et al., 2005) \\
\hline & Nhật Bản & 265 & $74 \%$ & $70-78 \%$ & (Hiratsuka et al., 2002) \\
\hline & Hàn Quốc & 104 & $74 \%$ & $68-80 \%$ & (Lim et al., 2014) \\
\hline & Tổng & 820 & $72 \%$ & $70-74 \%$ & \\
\hline & \multicolumn{5}{|c|}{$\chi^{2}=1,6830 ; p=0,3486$} \\
\hline \multirow{3}{*}{ Nam Á } & Ân Độ & 544 & $64 \%$ & $61-66 \%$ & (Krishnakumar et al., 2012) \\
\hline & Nepan & 200 & $70 \%$ & $66-74 \%$ & (Hassan et al., 2013) \\
\hline & Tồng & 744 & $65 \%$ & $63-68 \%$ & \\
\hline & \multicolumn{5}{|c|}{$\chi^{2}=0,3932 ; p=0,6318$} \\
\hline \multirow{5}{*}{$\begin{array}{l}\text { Đông Nam } \\
\text { Á }\end{array}$} & Thái Lan & 150 & $65 \%$ & $60-70 \%$ & (Veerakikosol et al., 2016) \\
\hline & Malaysia & 101 & $61 \%$ & $55-68 \%$ & (Ankathil et al., 2014) \\
\hline & Campuchia & 124 & $64,5 \%$ & $59-70 \%$ & (Hodel et al., 2013) \\
\hline & Việt Nam & 72 & $67 \%$ & $59-74 \%$ & (Veiga et al., 2009) \\
\hline & Tổng & 447 & $64 \%$ & $61-67 \%$ & \\
\hline & \multicolumn{5}{|c|}{$\chi^{2}=0,7266 ; p=0,4969$} \\
\hline \multirow{4}{*}{ Tây Á } & Thổ Nhĩ Kỳ & 115 & $92 \%$ & $88-95 \%$ & (Kayilioğlu et al., 2017) \\
\hline & Iran & 112 & $83 \%$ & $78-88 \%$ & (Azarpira et al., 2010) \\
\hline & Iraq & 100 & $98 \%$ & $96-100 \%$ & (Hamzah et al., 2018) \\
\hline & Tồng & 327 & $90,5 \%$ & $88-93 \%$ & \\
\hline & \multicolumn{5}{|c|}{$\gamma^{2}=64.1111: p<0.0001$} \\
\hline \multirow{5}{*}{ Da đen } & Mỹ-Phi & 146 & $27 \%$ & $22-33 \%$ & (Bhatnagar et al., 2009) \\
\hline & Nigeria & 179 & $16 \%$ & $12-20 \%$ & (Adehin et al., 2016) \\
\hline & Gambian & 288 & $21 \%$ & $18-24 \%$ & (Wojnowski et al., 2004) \\
\hline & Nam Phi & 320 & $14,5 \%$ & $12-17 \%$ & (Dandara et al., 2005) \\
\hline & Tồng & 933 & $19 \%$ & $17-21 \%$ & \\
\hline & \multicolumn{5}{|c|}{$\chi^{2}=238,9066 ; \mathrm{p}<0,0001$} \\
\hline \multirow{5}{*}{$\mathrm{Da}$ trắng } & Mỹ & 834 & $91 \%$ & $90-93 \%$ & (Plummer et al., 2003) \\
\hline & $\hat{\mathrm{Au}}$ & 1210 & $93 \%$ & $92-94 \%$ & (Dally et al., 2004) \\
\hline & Tổng & 2044 & $\begin{array}{l}3779 \\
(92 \%)\end{array}$ & $92-93 \%$ & \\
\hline & \multicolumn{5}{|c|}{$\chi^{2}=48,9845 ; \mathrm{p}<0,0001$} \\
\hline & \multicolumn{5}{|c|}{$\begin{array}{l}\text { n: Tổng số mẫu nghiên cứu. } \\
95 \% \text { CI: Khoảng tin cậy } 95 \% \text { cho tỷ lệ alen *3. } \\
\text { Các phép thống kê kiềm định chi bình phương }\left(\chi^{2}\right) \text { được thực hiện để so sánh } \\
\text { giữa các quần thể với quần thể người Kinh Việt Nam trong nghiên cứu này. } \\
\text { Độ tin cậy của các phép thông kê đều là } 95 \% \text {. }\end{array}$} \\
\hline
\end{tabular}




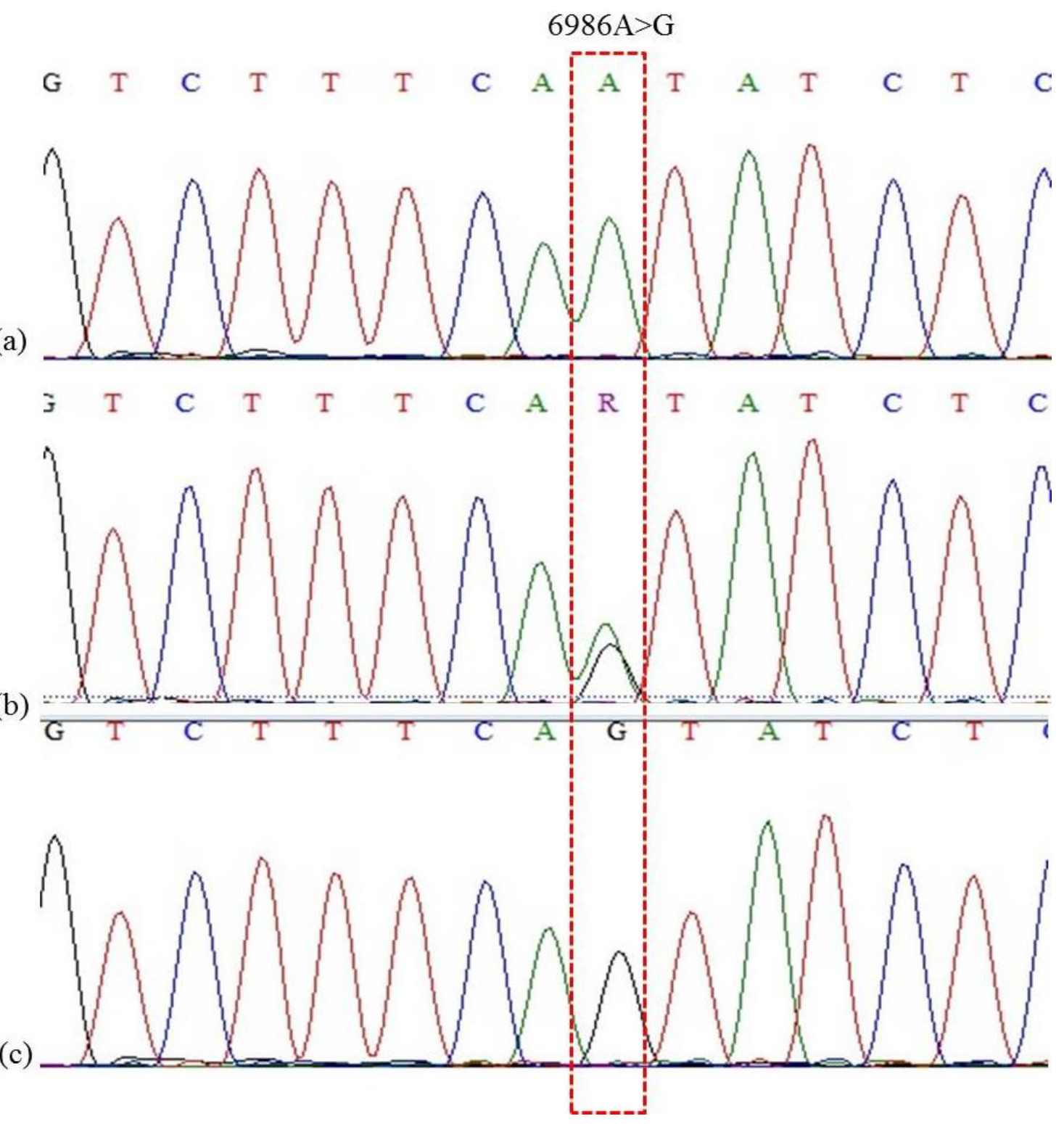

Hình 4. Kết quả giải trình tự Sanger của $C Y P 3 A 5 * 3$, (a) Đồng hợp tử kiểu dại $C Y P 3 A 5 * 1 / * 1$ (AA), (b) Dị hợp tử CYP3A5*1/*3 (AG), (c) Đồng hợp tử đột biến CYP3A5*3/*3 (GG)

\section{KÉT LUẬN}

Nghiên cứu này đã xác định được tần số kiểu gen và tần số alen của các biến thể CYP3A5*3 là $67.5 \%$ trên 100 người Kinh. Alen $C Y P 3 A 5^{*} 3$ là biến thể phổ biến nhất trong khi đó các biến thể *6, *8 và *9 không được tìm thấy trong nghiên cứu này. Kết quả này cho thấy nên tiến hành sàng lọc CYP $3 A 5^{*} 3$ trên bệnh nhân trước khi sử dụng các loại thuốc được chuyển hóa bởi enzyme này. Sự tồn tại của các biến thể gây ảnh hưởng tới chức năng của CYP3A5 như *6, *8 và *9 cần được làm rõ thêm trong các nghiên cứu xa hơn. Nghiên cứu của chúng tôi rất có ý nghĩa trong việc cung cấp dữ liệu về đa hình di truyền của $C Y P 3 A 5$, hỗ trợ làm giảm thiểu nguy cơ gặp phải các phản ứng có hại của thuốc và từ đó các bác sĩ có phương án sử dụng thuốc hiệu quả đối với mỗi bệnh nhân. 
Lò̀i cảm ơn: Công trình này được thực hiện với sự hỗ trợ kinh phí của Quý phát triển Khoa học và Công nghệ Quốc gia (NAFOSTED) cho TS. Nguyễn Hải Hà với mã số 106-YS.02-2014.30

\section{TÀI LIẸU THAM KHẢO}

Adehin A., Bolaji O., Kennedy M., 2016. Polymorphisms in CYP2C8 and CYP3A5 genes in the Nigerian population. Drug Metabolism and Pharmacokinetics, 32(3): 189-191.

Ankathil R., Zian A. A., Nizam Z. M., Azlan H., Baba A. A., 2014. P0223 CYP3A4* 18 and CYP3A5* 3 gene polymorphisms and imatinib resistance in Malaysian patients with chronic myeloid leukaemia. European Journal of Cancer, 50: e71-e72.

Azarpira N., Namazi S., Khalili A., Tabesh M., 2010. The investigation of allele and genotype frequencies of CYP3A5 $(1 * / 3 *)$ and P2Y12 (T744C) in Iran. Molecular biology reports, 38(8): 4873-4877.

Bhatnagar V., Garcia P. E., O'Connor T. D., Brophy V., Alcaraz J., Richard E., Bakris G., Middleton P. J., Norris K., Wright J., Hiremath L., Contreras G., Appel J. L., Lipkowitz M., 2009. CYP3A4 and CYP3A5 Polymorphisms and Blood Pressure Response to Amlodipine among African-American Men and Women with Early Hypertensive Renal Disease. American journal of nephrology, 31(2): 95-103.

Birdwell K. A., Decker B., Barbarino J. M., Peterson J. F., Stein C. M., Sadee W., Wang D., Vinks A. A., He Y., Swen J. J., Leeder J. S., van Schaik R., Thummel K. E., Klein T. E., Caudle K. E., MacPhee I. A. M., 2015. Clinical Pharmacogenetics Implementation Consortium (CPIC) Guidelines for CYP3A5 Genotype and Tacrolimus Dosing. Clinical pharmacology and therapeutics, 98(1): $19-24$.

Burk O., Koch I., Raucy J., Hustert E., Eichelbaum M., Brockmöller J., Zanger
U., Wojnowski L., 2004. The Induction of Cytochrome P450 3A5 (CYP3A5) in the Human Liver and Intestine Is Mediated by the Xenobiotic Sensors Pregnane X Receptor (PXR) and Constitutively Activated Receptor (CAR). Journal of Biological Chemistry 279(37): 3837938385.

Dai D., Tang J., Rose R., Hodgson E., Bienstock R. J., Mohrenweiser H. W., Goldstein J. A., 2001. Identification of variants of CYP3A4 and characterization of their abilities to metabolize testosterone and chlorpyrifos. The Journal of Pharmacology and Experimetnal Therapeutics, 299(3): 825-831.

Dally H., Bartsch H., Jäger B., Edler L., Schmezer P., Spiegelhalder B., Dienemann H., Drings P., Kayser K., Schulz V., Risch A., 2004. Genotype relationships in the CYP3A locus in Caucasians. Cancer letters, 207(1): 95-99.

Dandara C., Ballo R., Parker M., 2005. CYP3A5 genotypes and risk of esophageal cancer in two South African populations. Cancer letters, 225(2): 275282.

Danielson P., 2003. The Cytochrome P450 Superfamily: Biochemistry, Evolution and Drug Metabolism in Humans. Current Drug Metabolism, 3(6): 561-597.

Domanski T., Finta C., Halpert J., Zaphiropoulos G. P., 2001. cDNA cloning and initial characterization of CYP3A43, a novel human cytochrome P450. Molecular Pharmacology, 59(2): 386-392.

Hamzah I., Shafi F., Al-Huda N., A H Saeed A., 2018. Study the Association of CYP3A5 Polymorphism on the Risk of Breast Cancer in Some of the Iraqi Women. Journal of Global Pharma Technology, 10(8): 225-235.

Hassan R., Sadia Ameen S., Al Maruf A., Nandini A., Tabin H., Ahmed M., Islam M., Shahdaat Bin Sayeed M., Hasnat A., 2013. Genotype-phenotype variability in human CYP3A locus in Nepalese people 
residing in Bangladesh. International journal of clinical pharmacology and therapeutics, 51(3): 207-214.

Hiratsuka M., Takekuma Y., Endo N., Narahara K., Ismail Hamdy S., Kishikawa Y., Matsuura M., Agatsuma Y., Inoue T., Mizugaki M., 2002. Allele and genotype frequencies of CYP2B6 and CYP3A5 in the Japanese population. European journal of Clinical Pharmacology, 58(6): 417-421.

Hodel E. M. S., Csajka C., Ariey F., Guidi M., Kabanywanyi A. M., Duong S., Decosterd L. A., Olliaro P., Beck H.-P., Genton B., 2013. Effect of single nucleotide polymorphisms in cytochrome P450 isoenzyme and $\mathrm{N}$-acetyltransferase 2 genes on the metabolism of artemisininbased combination therapies in malaria patients from Cambodia and Tanzania. Antimicrobial agents and Chemotherapy, 57(2): 950-958.

Josephson F., Allqvist A., Janabi M., Sayi J., Aklillu E., Jande M., Mahindi M., Burhenne J., Bottiger Y., Gustafsson L. L., Haefeli W. E., Bertilsson L., 2007. CYP3A5 genotype has an impact on the metabolism of the HIV protease inhibitor saquinavir. Clinical Pharmacology \& Therapeutics, 81(5): 708-712.

Kayilioğlu H., Kocak U., Kan D., F. Percin E., Sal E., Tekkeşin F., Isik M., Oner N., Belen B., Keskin E., Okur A., Albayrak M., Kaya Z., Pinarli F., Yenicesu I., Karadeniz C., Oguz A., Gursel T., 2017. Association of CYP3A5 Expression and Vincristine Neurotoxicity in Pediatric Malignancies in Turkish Population. Journal of Pediatric Hematology/Oncology, 39(6): 458-462.

Koch I., Weil R., Wolbold R., Brockmöller J., Hustert E., Burk O., Nuessler A., Neuhau s P., Eichelbaum M., Zanger U., 2002. Interindividual variability and tissuespecificity in the expression of cytochrome P450 3A mRNA. Drug Metabolism and Disposition 30(10): 1108-1114.
Krishnakumar D., Gurusamy U., Dhandapani K., Surendiran A., Baghel R., Kukreti R., Gangadhar R., Prayaga U., Manjunath S., Adithan C., 2012. Genetic polymorphism s of drug-metabolizing phase I enzymes CYP2E1, CYP2A6 and CYP3A5 in South Indian population. Fundamental \& Clinical Pharmacology, 26(2): 295-306.

Kuehl P., Zhang J., Lin Y., Lamba J., Assem M., Schuetz J., Watkins P. B., Daly A., Wrighton S. A., Hall S. D., Maurel P., Relling M., Brimer C., Yasuda K., Venkataramanan R., Strom S., Thummel K., Boguski M. S., Schuetz E., 2001. Sequence diversity in CYP3A promoters and characterization of the genetic basis of polymorphic CYP3A5 expression. Nat Genet, 27(4): 383-791.

Lamba J., Hebert J. M., Schuetz E. G., Klein T. E., Altman R. B., 2012. PharmGKB summary: very important pharmacogene information for CYP3A5. Pharmacogenet Genomics, 22(7): 555-558.

Lamba J. K., Lin Y. S., Schuetz E. G., Thummel K. E., 2002. Genetic contribution to variable human CYP3Amediated metabolism. Advanced Drug Delivery Reviews, 54(10): 256-269.

Langman L., van Gelder T., Schaik R., 2016. Pharmacogenomics Aspect of Immunosuppressant Therapy. Personalized Immunosuppression in Transplantation: 109-124.

Lee S. J., Usmani K., Chanas B., Ghanayem B., Xi T., Hodgson E., Mohrenweiser H., Goldstein J., 2003. Genetic findings and functional studies of human CYP3A5 single nucleotide polymorphisms in different ethnic groups. Pharmacogenetics and Genomics 13(8): 461-472.

Lewis F. V. D., 2004. 57 varieties: The human cytochromes P450. Pharmacogenomics 5(3): 305-318.

Lim Y. J., Cha E. Y., Jung H. E., Ghim J. L., Lee S. J., Kim E. Y., Shin J. G., 2014. Genetic polymorphisms of CYP2C9, CYP2C19, CYP2D6, CYP3A4, and 
Vu Phuong Nhung et al.

CYP3A5 in Vietnamese-Koreans. Translational and Clinical Pharmacology 22(2): 70-77.

Liu C. H., Peck K., Huang J. D., Lin M. S., Wang C. H., Hsu W. P., Wang H. W., Lee H. L., Lai M. L., 2005. Screening CYP3A single nucleotide polymorphisms in a Han Chinese population with a genotyping chip. Pharmacogenomics 6(7): 731-747.

Lolodi O., Wang Y., Wright W., Chen T., 2017. Differential Regulation of CYP3A4 and CYP3A5 and its Implication in Drug Discovery. Current Drug Metabolism 18(12): 1095-1105.

Nebert W. D., Wikvall K., Miller L. W., 2013. Human cytochromes P450 in health and disease. Philosophical transactions of the Royal Society of London. Series B: Biological sciences, 368(1612): 20120431.

Ozdemir V., Kalow W., Tang B. K., Paterson A. D., Walker S. E., Endrenyi L., Kashuba A. D. M., 2000. Evaluation of the genetic component of variability in CYP3A4 activity: A repeated drug administration method. Pharmacogenetics and Genomics, 10(5): 373-388.

Plummer J. S., Conti V. D., Paris L. P., Curran A., Casey G., Witte S. J., 2003. CYP3A4 and CYP3A5 genotypes, haplotypes, and risk of prostate cancer. Cancer Epidemiology, Biomarkers and Prevention, 12(9): 928-932.

Rahmioglu N., Heaton J., Clement G., Gill R., Surdulescu G., Zlobecka K., Hodgkiss D., Ma Y., Hider R., Smith N., R Ahmadi K., 2011. Genetic epidemiology of induced CYP3A4 activity. Pharmacogenetics and Genomics 21: 642-651.

Rendic S., 2002. Summary of information on human CYP enzymes: human P450 metabolism data. Drug Metabolism Reviews, 34(1-2): 83-448.

Sarasamma S., Gracious N., Nair S. S., Radhakrishnan R., 2016. Pharmacogenomics of CYP3A5 Polymorphism: Predicting Dose-adjusted
Trough Levels of Tacrolimus in South Indian Renal Transplant Patients. Journal of Pharmacogenomics and Pharmacoproteomics, 7(3): 1-5.

Schuetz D. J., Kauma S., Guzelian P., 1993. Identification of the fetal liver cytochrome CYP3A7 in human endometrium and placenta. The Journal of Clinical Investigation, 92(2): 1018-1024.

Schuetz D. J., Beach L. D., Guzelian P., 1994. Selective expression of cytochrome P450 CYP3A mRNAs in embryonic and adult human liver. Pharmacogenetics and Genomics, 4(1): 11-20.

Tateishi T., Watanabe M., Moriya H., Yamaguchi S., Sato T., Kobayashi S., 1999. No ethnic difference between Caucasian and Japanese hepatic samples in the expression frequency of CYP3A5 and CYP3A7 proteins. Biochemical Pharmacology, 57(8): 935-939.

Veerakikosol K., Chariyavilaskul P., Townamchai N., Wittayalertpanya S., 2016. Association of CYP3A5 and POR polymorphisms with the maintenance tacrolimus dosage requirement in Thai recipients of kidney transplants. Asian Biomedicine, 10(5): 483-490.

Veiga M. I., Asimus S., Ferreira P. E., Martins J. P., Cavaco I., Ribeiro V., Hai T. N., Petzold M. G., Björkman A., Ashton M., Gil J. P., 2009. Pharmacogenomics of CYP2A6, CYP2B6, CYP2C19, CYP2D6, CYP3A4, CYP3A5 and MDR1 in Vietnam. European Journal of Clinical Pharmacology, 65(4): 355-363.

Werk A. N., Lefeldt S., Bruckmueller H., Hemmrich-Stanisak G., Franke A., Roos M., Kuchle C., Steubl D., Schmaderer C., Brasen J. H., Heemann U., Cascorbi I., Renders L., 2014. Identification and characterization of a defective CYP3A4 genotype in a kidney transplant patient with severely diminished tacrolimus clearance. Clinical Pharmacology \& Therapeutics, 95(4): 416-422. 
Westlind-Johnsson A., Malmebo S., Xie H. G., Wood A., Kim B. R., Michael Johansson A., Otter C., Andersson T. B., Johansson I., Edwards R. J., Boobis A. R., Ingelman-Sundberg M., 2003. Comparative analysis of CYP3A expression in human liver suggests only a minor role for CYP3A5 in drug metabolism. Drug Metabolism and Disposition 31(6): 755-761.

Wojnowski L., Turner P., Pedersen B., Hustert E., Brockmöller J., Mendy M., Whittle C. H., Kirk G., Wild P. C., 2004. Increased levels of aflatoxin-albumin adducts are associated with CYP3A5 polymorphisms in The Gambia, West Africa. Pharmacogenetics and Genomics 14(10): 691-700. Stein C., Wilkinson R. G., 2004. Genetic variability in CYP3A5 and its possible consequences. Pharmacogenomics 5(3): 243-272.

Zanger U. M. ,Schwab M., 2013. Cytochrome P450 enzymes in drug metabolism: Regulation of gene expression, enzyme activities, and impact of genetic variation. Pharmacology and Therapeutics 138(1): 103-141.

Zanger U. M., Turpeinen M., Klein K., Schwab M., 2008. Functional pharmacogenetics/genomics of human cytochromes P450 involved in drug biotransformation. Analytical and Bioanalytical Chemistry 392(6): 1093-1108. 